\title{
Study on Sustainable Development of Mining Cities by the Method of Relative Resources Carrying Capacity and GM $(1,1)$ Model
}

\author{
Keyu Bao ${ }^{1}$, Gang He ${ }^{1,2 *}$, Lan Jin ${ }^{1}$, Jingwen Yang ${ }^{1}$, Qingting Zhou ${ }^{1}$ \\ ${ }^{1}$ College of Economy and Management, Anhui University of Science and Technology, Huainan, Anhui, 232001, China \\ ${ }^{2}$ State Key Laboratory of Mining Response and Disaster Prevention and Control in Deep Coal Mines, \\ Huainan, Anhui, 232001, China
}

Received: 19 December 2019

Accepted: 2 March 2020

\begin{abstract}
Mining cities in China are vital energy bases that contribute greatly to the country's development. With the pressure of resources depletion and environmental destruction, the sustainable development of these cities is increasingly concerned by the government. This study chooses typical mining cities in Anhui Province of China as the case studies, then selects ten indicators from four dimensions of natural, economic, social, and environmental resources and improves the relative resources carrying capacity (RRCC) model. The dynamic changes of RRCC of these cities from 2007 to 2017 are analyzed. Then the predicted values in 2018-2023 were gotten based on GM $(1,1)$ model. The results indicate that: (1) Overall, the RRCC of these cities are overload and the overload population has slightly decreased. (2) The primary resources carrying the population are natural resources, but their carrying capacity shows a declining trend. The carrying capacities of economic, social, and environmental resources are much less than that of natural resources, although they have increased a lot in these years. (3) The RRCC and its variation tendency of each mining city are different. (4) The predicted RRCC of these cities would become stronger and the population overload would decrease in the next six years.
\end{abstract}

Keywords: sustainable development, mining cities, relative resources carrying capacity, GM model, Anhui Province

\section{Introduction}

Mineral resources are the foundation of production and development for human activities. In China, mineral resources provide $90 \%$ of its primary energy, $80 \%$ of its industrial raw materials, $70 \%$ of its agricultural means of production, and $30 \%$ of its domestic water [1]. National mineral resources planning (2016-2020) indicates that as China is still in the middle stage of industrialization, the demand for energy resources will remain high, although the growth rate of the demand is currently slowing. 
Mining cities in China are numerous and widely distributed: there are currently 240 mining cities and more than 11 million mining employees [2]. These cities are important for the sustainable and healthy development of the national economy and they guarantee crucial energy resources guarantee for China. However, these mining cities are facing increasingly prominent problems: economic growth is still strongly dependent on the mining industry, and the development of alternative industry is lagging. Additionally, the exploitation intensity of mineral resources is high while the comprehensive utilization level is low. Meanwhile, the ecological environments of these cities have experienced serious damage. Air and water pollution [3-4], land and vegetation destruction [5], and geological disasters [6] occur frequently. Therefore, the sustainable development of mining cities has become a key focus of governmental departments. To create a sustainable development policy for mining cities, it is necessary to scientifically evaluate their resources carrying capacity and determine their supportive and restrictive resources.

The concept of "carrying capacity" was put forward by Parker et al. in 1921 and the definition was described as "The maximum amount of a certain species in a specific environmental condition" [7]. The meaning of this concept becomes more specific with deeper research in this field. As for now, the definition accepted mostly is "The quantity and quality of resources in a country or a region which supports the basic survival and development of the population in it" [8]. In the related research on resources carrying capacity (RCC), mining cities have become the research hot spots gradually because of their vulnerable ecological environment and the single way of economic growth. Many scholars studied on the RCC of mining cities from aspects of water resources [9], land resources [10], mineral resources [11], ecological or environmental resources [12], economic resources [13], and comprehensive resources carrying capacity [14]. These studies revealed the situation of different RCC in mining cities successfully.

Most of the previous research on RRC usually regards the study area as a closed and isolated system to investigate the bearing capacity of a specific resource to the population from a single perspective [15]. But because of the enormous population and unevenly distributed resources in China, when measuring the population carried by resources with previous methods, the results always show that the population is much larger than the resources carrying capacity. Obviously, these results are of limited practical significance [16].

Aim at these problems existing in research, Huang et al. proposed a new concept named "relative resources carrying capacity" (RRCC) [17]. The evaluation method of RRCC is taking one or several regions larger than the study area as the reference area, and then the RCC of various resources of the study area is calculated according to per capita resources and the resource stock of the research area. Compared with previous methods, RRCC can not only reflect the gap between the carrying capacity of each kind of resources and the number of population in an area intuitively but also identify the superior resources and inferior resources distinctly. Accordingly, the theory of RRCC has provided a new view in the evaluation of regional resources carrying capacity and the study of the relationship between population distribution and resource utilization; it has become an important evaluation standard of sustainable development [18-19].

In the light of recent relative literature, the main research perspective could be got. Pei and Yang considered Tianshui city and Jiangsu Province as case studies to explore the temporal variation and spatial distribution characteristics of RRCC [20-21]. Li studied the RRCC of Wumeng Mountain then found that the main resources supporting the population were land resources [22]. Wang divided the cities in the Tarim River Basin into four types based on the theory of RRCC [23]. Wang and Fu researched the RRCC in typical ecologically fragile areas and proposed specific and practical suggestions for sustainable development [24-25].

Previous studies evaluating RRCC have been relatively useful; however, there is a lack of research involving the RRCC of mining cities. Moreover, the evaluation models used in the existing literature have often contained just two indicator dimensions: natural and economic resources, and their indicators were likely inadequate. With the development of science and increase in cross-regional economic activity, the demand for natural resources will reduce gradually; meanwhile, economic, social and environmental resources will provide more support to development [26]. Therefore, traditional evaluation models are incomplete because they do not provide the system for comprehensive evaluation. Moreover, the calculations of the traditional models were not entirely objective because the weights of the indicators were always determined subjectively, and there were few studies focused on RRCC predictions.

Based on traditional evaluation models and related literature, combined with the characteristics of mining cities, this study selects ten mining cities in Anhui Province as the case studies [27-30]. Subsequently, based on the four dimensions of natural, economic, social and environmental resources, ten indicators are selected to construct the evaluation system. With the help of LINGO11.0 (Linear Interactive and General Optimizer) software and the GM $(1,1)$ model, the RRCC of these cities is analyzed and predicted; the supportive and restrictive resources of these cities are also identified. This study is expected to expand and supplement the research on RRCC and provide theoretical support and a foundation for decision-making for the formulation of regional sustainable development policies. 


\section{Materials and Methods}

\section{Study Area}

Anhui Province, located in the interior of eastern China, is a crucial energy base of Yangtze River Delta economic zone [31], a link between eastern and western regions, and a region carrying on industrial transfer from the developed coastal areas [32]. The mineral resources in Anhui are rich and various, among which the reserves of coal, iron, copper, iron pyrite, alum and limestone all occupy the top ten in China [33].

In 2017, the province's total energy output was 91.44 million tons of standard coal. There was a yield of 117.24 million tons of raw coal, 37.26 million tons of iron ore and 166,000 tons of copper in that year. Now there are 16 cities in Anhui Province, and 10 of them are mining cities. The brief information of these mining cities is listed in Table 1.

\section{The Evaluation System}

Demand for various resources has increased and natural resources such as water, forest, and minerals are considered as indicators and are included in the evaluation system [34-35]. Except for natural and economic resources, social and environmental resources have also been embraced in evaluations due to their increasingly important roles in socio-economic development [36]. In combining the characteristics of the investigated area and relevant literature, an evaluation system of RRCC is established, and relative indicators are determined.

\section{Indicators of Natural Resources}

(1) Water resources: Water resources are indispensable to human production and life and it is

Table 1. Ten mining cities in Anhui Province.

\begin{tabular}{|c|c|c|c|}
\hline $\begin{array}{c}\text { Mining } \\
\text { Cities }\end{array}$ & $\begin{array}{c}\text { Main mining } \\
\text { resources }\end{array}$ & District & Type \\
\hline Bozhou & Coal & North & Mature \\
\hline Huaibei & Coal & North & Declining \\
\hline Huainan & Coal & Central & Mature \\
\hline Suzhou & Coal & North & Mature \\
\hline Fuyang & Coal & North & Growing \\
\hline Ma Anshan & Iron & East & Regenerating \\
\hline Tongling & Copper & South & Declining \\
\hline Xuancheng & Calcite & South & Mature \\
\hline Chizhou & Manganese, Calcite & South & Mature \\
\hline Chuzhou & $\begin{array}{c}\text { Attapulgite clay } \\
\text { Quartzite, Rock salt }\end{array}$ & East & Mature \\
\hline
\end{tabular}

crucial to sustainable development. In this paper, the total amount of water resources is chosen as an indicator of water resources.

(2) Land resources: Cultivated land resources, which play an irreplaceable role in agriculture and national economy, are the essential natural resources to China who has the largest population in the world. Some literature selects cultivated area as the indicator of land resources. But because of the vast land area of China, climatic conditions are different in different regions, and this leads to various farming conditions [37]. So cultivated area cannot indicate land output well. As the influence of varying farming conditions and the multiple cropping index, the total sown area of crops is considered as the indicator.

(3) Energy resources: The mineral resources are rich and various in Anhui Province. By the end of 2015, 158 kinds of minerals (including subspecies) have been discovered. Energy resources are important for regional development. Therefore, total energy production is selected as the indicator of energy resources to evaluate the RCC of natural resources.

\section{Indicators of Economic Resources}

(1) Economic output resources: As an ideal index measuring national or regional economic conditions, GDP is often used in evaluation systems. It can reflect the economic level and market size of a country or a region.

(2) Social consumer goods resources: The indicator of social consumer goods resources is the total retail sales of consumer goods. This indicator is the most direct one representing domestic consumer demand, and it is usually used to research local retail market changes and reflect economic prosperity degree.

\section{Indicators of Social Resources}

(1) Human resources: Humans are the core of socialeconomic activity and their behavior would influence the systems of resources, environment, economy and society. Humans improve resources carrying capacity by raising the level of science and technology and increasing productivity. The quality of human resources will impact the RRCC eventually. So human resources are included in social resources dimension and the representational indicator is the number of people with higher education.

(2) Science and technology resources: Science and technology, the driving forces of social progress, can be used to promote resources utilization, conserve existing resources and explore new resources. To represent the level of science and technology, research and development expenditures (R\&D) is chosen as the evaluation indicator in this paper.

(3) Medical resources: Medical resources are related to public health and social security, and sufficient medical resources are good for promoting 
the living condition of residents and enhancing social carrying capacity. The number of medical institutions can represent the amount of social medical resources. So this indicator is often used to evaluate the social development level.

\section{Indicators of Environmental Resources}

(1) Green land resources: As for green land resources, the urban green area is selected as the indicator. Urban green area refers to the area used for gardening and greening in cities. It is thought that the larger the urban green area, the better the city's environment is.

(2) Capital resources for environmental protection: Urban environment is essential for sustainable development as it provides space for production and living, and it has the ability, to contain and decontaminate waste. These functions of urban environment can be named as the carrying capacity. However, the carrying capacity of one city's environment is limited. In order to keep the carrying capacity, protecting the environment in many ways is necessary. Total investment in environmental pollution control is an indicator that reflects the overall level of environmental protection in an area. To some extent, it can represent the potential carrying capacity of the environment.

\section{Evaluation Model}

\section{The Model of RRCC}

Based on the traditional model and the characteristics of social-economic development of ten mining cities in Anhui Province, this paper selects the country of China (except for Hong Kong, Macau and Taiwan) and the ten mining cities as reference areas, respectively; and constructs the RRCC evaluation system by using the evaluation indexes selected (Table 2). The RRCC of natural, economic, social, and environmental resources are got by calculation first; then the related synthetic resources carrying capacity (RSRCC) is worked out.

The procedures of calculation are described as follows:

$$
C_{i}=I_{i} \times Q_{i}
$$

In formula (1), $C_{i}$ is the RRCC of the $i t h$ resource; $I_{i}$ is the carrying index of the ith resource; $Q_{i}$ is the total amount of the ith resource in the study area.

$$
I_{i}=P_{o} / Q_{i o}
$$

In formula (2), $P_{o}$ is the population of the reference area; $Q i_{o}$ represents the total amount of the ith resource in the reference area.

$$
C_{n}^{\prime}=C_{1} W_{1}+C_{2} W_{2}+C_{3} W_{3}
$$

In formula (3), $C_{n}$ ' is the RRCC of natural resources; $C_{1}, C_{2}, C_{3}$ are the RRCC of water resources, land resources and energy resources; $W_{i}$ is the weight of each RRCC, $W_{1}+W_{2}+W_{3}=1$.

$$
C_{e C o}^{\prime}=C_{4} W_{4}+C_{5} W_{5}
$$

In formula (4), $C_{\text {eco }}$ ' is the RRCC of economic resources; $C_{4}, C_{5}$ are the RRCC of economic output resources and social consumer goods resources. $W_{i}$ is the weight of each RRCC, $W_{4}+W_{5}=1$.

$$
C_{s o}^{\prime}=C_{6} W_{6}+C_{7} W_{7}+C_{8} W_{8}
$$

In formula (5), $C_{s o}$ ' is the RRCC of social resources;

\begin{tabular}{|c|c|c|}
\hline Overall goal & First-level indexes & Second-level indexes \\
\hline \multirow{10}{*}{$\begin{array}{l}\text { Relative resources } \\
\text { carrying capacity }\end{array}$} & \multirow{3}{*}{ Natural resources } & Water resources \\
\hline & & Land resources \\
\hline & & Energy resources \\
\hline & \multirow{2}{*}{ Economic resources } & Economic output resources \\
\hline & & Social consumer goods resources \\
\hline & \multirow{3}{*}{ Social resources } & Human resources \\
\hline & & Science and technology resources \\
\hline & & Medical resources \\
\hline & \multirow{2}{*}{ Environmental resources } & Green land resources \\
\hline & & Capital resources for environmental protection \\
\hline
\end{tabular}
$C_{6}, C_{7}, C_{8}$ are the RRCC of human resources, science and technology resources and medical resources. $W_{i}$ is the weight of each RRCC, $W_{6}+W_{7}+W_{8}=1$.

Table 2. The evaluation index system of RRCC of mining cities in Anhui Province. 


$$
C_{e n}^{\prime}=C_{9} W_{9}+C_{10} W_{10}
$$

In formula (6), $C_{e n}$ ' is the RRCC of environmental resources; $C_{9}, C_{10}$ are the RRCC of green land resources and capital resources for environmental protection. $W_{i}$ is the weight of each RRCC, $W_{9}+W_{10}=1$.

$C_{s}{ }^{\prime}=C_{n}{ }^{\prime} W_{11}+C_{\varepsilon c o}{ }^{\prime} W_{12}+C_{s o}{ }^{\prime} W_{13}+C_{e n}{ }^{\prime} W_{14}$

In formula (7), $C_{s}$ ' is the RSRCC, $W_{i}$ is the weight of each RRCC, $W_{11}+\stackrel{s}{W}_{12 \mathrm{v}}+W_{13}+\mathrm{W}_{14}=1$.

\section{Further Improvement of the Model}

At the early stage of relevant research, the weights in the equations were determined subjectively. But this would make the calculation method somewhat unscientific. As there are always only a few indexes in each equation, it is hard to use common methods such as AHP, PCA or entropy method to get weights. Therefore, this study selected the way of linear optimization [38] and used LINGO11.0 software to calculate the optimal solution of the weights objectively.

Taking the RRCC of natural resources for example, the improved model is as follows:

$$
\begin{aligned}
\max C_{n} & =C_{\mathbf{1}} W_{\mathbf{1}}+C_{\mathbf{2}} W_{\mathbf{2}}+C_{\mathbf{3}} W_{\mathbf{3}} \\
\min C_{n} & =C_{\mathbf{1}} W_{\mathbf{1}}+C_{\mathbf{2}} W_{\mathbf{2}}+C_{\mathbf{3}} W_{\mathbf{3}}
\end{aligned}
$$

...where $\max C_{n}$ and min $C_{n}$ are the maximum value and minimum value of the RRCC of natural resources. Meanwhile, equations (8-9) are under following constraints:

$$
\begin{gathered}
\mathrm{a} \leq\left|W_{X}-W_{y}\right| \leq b, \mathrm{c}<W_{x}, W_{y}<1 \\
(\mathrm{x}, \mathrm{y}=1,2,3 \& \mathrm{x} \neq \mathrm{y}), \sum_{x=1}^{3} W_{x}=1, \sum_{y=1}^{3} W_{y}^{\prime}=1
\end{gathered}
$$

The letters $\mathrm{a}$ and $\mathrm{b}$ are the lowest and the highest difference between the weights of $W_{1}, W_{2}$ and $W_{3}$; and $\mathrm{c}$ is the lowest value of each weight. With the help of LINGO11.0, $\max C_{n}$ and $\min C_{n}$ which meet the above constraints are carried out. Then the final value of $C_{n}$ is calculated by equation (12):

$$
C_{n}=\sqrt{\max C_{n} * \min C_{n}}
$$

The values of the RRCC of other three dimensions and the RSRCC can be worked out in a similar way. Next, the population which exceeds the RSRCC is got by equation (13).

$$
\mathbf{P}^{\prime}=\mathbf{P}-C_{s}
$$

In formula (13), $\mathrm{P}^{\prime}$ is the population overloaded; $\mathrm{P}$ is the actual population, $\mathrm{C}_{\mathrm{s}}$ is the RSRCC. According to the value of $\mathrm{P}^{\prime}$, the carrying states are divided into three levels: overload $\left(\mathrm{P}^{\prime}>0\right)$, surplus $\left(\mathrm{P}^{\prime}<0\right)$, critical $\left(\mathrm{P}^{\prime}=0\right)$.

$$
\mathrm{R}=P^{\prime} / P
$$

In formula (14), $\mathrm{R}$ is the overload rate which reflects the overload scale.

\section{The GM $(1,1)$ Model}

In order to understand the trend of the RSRCC in the next few years, this study considered using mathematical models to predict the population and the RSRCC from 2018 to 2023. Now the mathematical models often used in predicting include regression prediction models [39], BP (back propagation) network models [40], ARIMA models [41], and Grey models [42]. The choice of the model is largely subject to the characteristics of the sample data and each model. Regression prediction models are simple and large sample data with good distribution regularities are required when using these models. The design of structures in BP network models is difficult, and these models always result in the problem of local minimum and they cannot achieve the overall optimal because of the nonlinear gradient optimization algorithm [43]. Abundant stable time series data are needed if you choose ARIMA models. Grey models are very useful when the sample is small, the data are insufficient and the system is uncertain. They aim at uncertain systems which include both known information and unknown information. There is no requirement for the quantity or regular distribution of samples in Grey models [44]. In view of the small sample and uncertain system of this study, Grey models were selected as the prediction method.

Grey models developed rapidly and they have been used widely and successfully in many fields in the last few decades, such as analysis of regional environmental carrying capacity [45], prediction of population [46], research on the disease development trend [47], estimation of the wind power [48], prediction of the coal and gas outburst [49], early warning of mechanical fault [50] and so on. In Grey models, GM $(1,1)$ model is most often used because of its advantages of high accuracy, simplicity, and no requirement for typical probability distribution [51]. Its basic principle is as follows:

Let the original series be $x^{(0)}=\left\{x^{(0)}(1), x^{(0)}(2)\right.$, $\left.x^{(0)}(3) \ldots x^{(0)}(n)\right\}$, then the new series $x^{(1)}=\left\{x^{(1)}(1)\right.$, $\left.x^{(1)}(2), \quad x^{(1)}(3) \ldots x^{(1)}(n)\right\} \quad$ can be gotten by defining $x^{(1)}(k)=\sum_{i=1} x^{(0)}(i),(k=1,2, \ldots n)$.

So the differential equation of $\operatorname{GM}(1,1)$ is as follows:

$$
d x^{(1)} / d t+a x^{(1)}=b
$$

...where $a$ is the development coefficient, $b$ is the grey influencing coefficients and $t$ is the serial number of 
time. After solving formula (15), the standard form of GM $(1,1)$ model is carried out:

$$
\hat{x}^{(1)}(t+1)=\left[x^{(0)}(1)-\frac{b}{a}\right] e^{-a t}+\frac{b}{a}
$$

Then transform formula (16) into the prediction model of the original series:

$$
\hat{x}^{(0)}(t+1)=(1-e)\left[x^{(0)}(1)-\frac{b}{a}\right] e^{-a k}
$$

It is necessary to test the fitting accuracy of GM $(1,1)$ model after it has been built. Only the models which have prefect fitting accuracy could be used in prediction. There are three kinds of test methods: correlation test, residual test and posterior error test. Posterior error test is usually used to examine the accuracy of GM $(1,1)$ model. The process of this test is as follows:

Firstly, the mean square error $\left(s_{0}\right)$ of the original series should be calculated.

$\bar{x}=\frac{1}{n} \sum_{i=1}^{n} x^{(0)}(i), S_{0}^{2}=\sum_{i=1}^{n}\left[x^{(0)}(i)-\bar{x}\right], S_{0}=\sqrt{\frac{S_{0}^{2}}{n-1}}$

Secondly, the mean square error $\left(s_{1}\right)$ of the residual series is calculated.

$\bar{\varepsilon}=\frac{1}{n} \sum_{i=1}^{n} \varepsilon^{(0)}(i), S_{1}^{2}=\sum_{i=1}^{n}\left[\varepsilon^{(0)}(i)-\bar{\varepsilon}\right], S_{1}=\sqrt{\frac{S_{1}^{2}}{n-1}}$

In formula $(19), \varepsilon^{(0)}(i)=x^{(0)}(i)-\hat{x}^{(0)}(i)$. Finally, ratio of $s_{1}$ and $s_{0}(c)$, and small error probability $(p)$ are carried out.

$$
\begin{gathered}
c=\frac{S_{1}}{S_{0}} \\
p=\left\{\left|\varepsilon^{(0)}(i)-\bar{\varepsilon}\right|<0.6745_{S_{0}}\right\}
\end{gathered}
$$

Table 3. The fitting accuracy level of GM $(1,1)$ model.

\begin{tabular}{|c|c|c|}
\hline Fitting accuracy level & $\begin{array}{c}\text { Small error } \\
\text { probability (p) }\end{array}$ & $\begin{array}{c}\text { Ratio of } \mathrm{S}_{1} \text { and } \\
\mathrm{S}_{0}(\mathrm{c})\end{array}$ \\
\hline Excellent & $\mathrm{p} \geq 0.95$ & $\mathrm{c} \leq 0.35$ \\
\hline Qualified & $0.95>\mathrm{p} \geq 0.80$ & $0.35<\mathrm{c} \leq 0.50$ \\
\hline Barely qualified & $0.80>\mathrm{p} \geq 0.70$ & $0.50<\mathrm{c} \leq 0.65$ \\
\hline Unqualified & $0.70>\mathrm{p}$ & $0.65<\mathrm{c}$ \\
\hline
\end{tabular}

The fitting accuracy of GM $(1,1)$ model, shown in Table 3 , is graded to 4 levels according to the value of $c$ and $p$.

\section{Results}

\section{Analysis of the RRCC of the Ten Mining Cities}

\section{The RSRCC}

As shown in Fig. 1, the RSRCC of these ten mining cities was much smaller than the actual population from 2007 to 2017 when considering the country as a reference. According to statistics, up to 2017, the population density of these cities was 553.6 per $\mathrm{km}^{2}$, which was almost five times higher than that of the country. Their large population posed pressure on resources and the sustainable development of these mining cities. The carrying state was always overloaded, although the RSRCC increased during those years (Table 4). The gap between the actual population and the RSRCC peaked in value at 19.32 million in 2011, and the overall overload situation showed a decreasing trend. The reason was that the growth rate of the actual population was less than that of the RSRCC; the actual population increased from 40.33 million to 42.8 million while the RSRCC increased from 21.88 million to 25.45 million during the study period.

\section{The RRCC of Natural Resources}

The RRCC of natural resources had the highest value among the four resources with a mean value of 39.16 million, and it was even higher than the population from 2007 to 2009. However, its overall trend was downward, decreasing from 44.28 million to 37.34 million. As shown in Fig. 2, the average RRCC of each indicator was uneven. Energy resources played the most important role in the population carrying capacity as the average RRRC was 21.37 million. The high carrying capacity of natural resources indicated that the development of these mining cities relied mainly on natural resources, especially energy resources. Meanwhile, the diminishing scale of the RRCC for natural resources meant that the carrying capacity of natural resources declined, and the developing mode that depended mainly on natural resources was unsustainable.

\section{The RRCC of Environmental Resources}

The RRCC of environmental resources has exceeded the RRCC of economic and social resources since 2008. Rising from 15.32 million to 24.14 million, the RRCC of the environment had become a growing power for population carrying. Considering the two indicators belonging to environmental resources, the average RRCC of green land resources was 12.35 million and that 


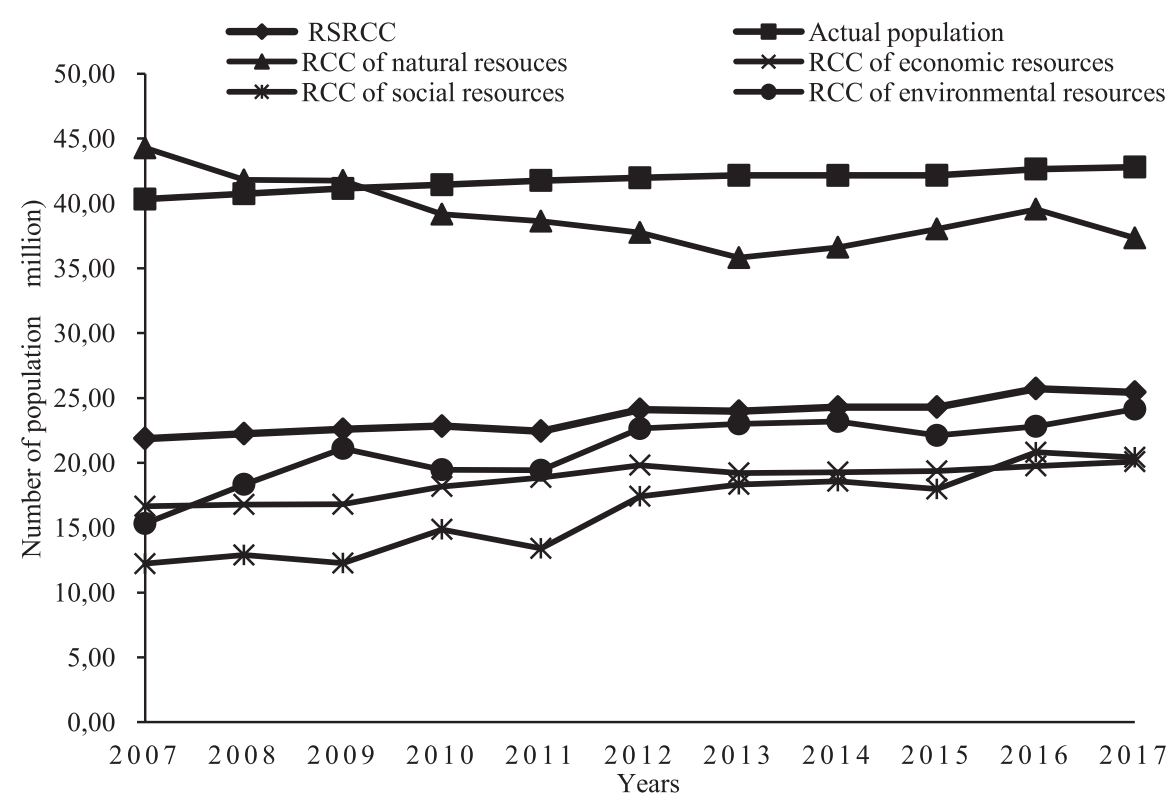

Fig. 1. The changing trend of RRCC of mining cities in Anhui Province from 2007 to 2017.

of environmental protection was 8.61 million. Relevant data indicated that the urban green land area and the investment in environmental protection increased by $56 \%$ and $93 \%$, respectively, during the study period. Because of the policy of curtailing production and protecting the environment in the country, these mining cities had shut down mining enterprises with low capacities and enhanced environmental governance. Consequently, their local environments improved, and the RRCC of environmental resources increased.

\section{The RRCC of Economic and Social Resources}

The RRCC of economic and social resources were the lowest, and the carrying status remained considerably overloaded despite their carrying capacity showing an upward tendency from 2007 to 2017 . The carrying status of economic and social resources revealed that the level of economic and social development in these mining cities was not in accordance with the population.

The changes in trends of the two kinds of RRCC were different. In the light of Fig. 1, the RRCC of economic resources was dramatically larger than that of social resources from 2007 to 2012; but the difference began to decrease after 2013; ultimately, the RRCC of social resources exceeded that of economic resources from 2016 onward. The RRCC of social resources increased from 12.22 million to 20.42 million (67.1\%) and the RRCC of economic resources increased from 16.65 million to 20.09 million $(20.67 \%)$. These data showed that the carrying capacity of social resources improved a lot and might maintain its upward tendency in future years. As shown in Fig. 2, human resources contributed most to the carrying capacity of social

Table 4. The RRCC of mining cities in Anhui Province from 2007 to 2017.

\begin{tabular}{|c|c|c|c|c|c|c|c|c|c|}
\hline Year & $\mathrm{C}_{\text {nat }}$ & $\mathrm{C}_{\text {eco }}$ & $\mathrm{C}_{\mathrm{so}}$ & $\mathrm{C}_{\mathrm{en}}$ & $\mathrm{C}_{\mathrm{s}}$ & $\mathrm{P}$ & $\mathrm{P}^{\prime}$ & $\mathrm{R}$ & Carrying State \\
\hline 2007 & 44.28 & 16.65 & 12.22 & 15.32 & 21.88 & 40.33 & 18.45 & 0.46 & Overload \\
\hline 2008 & 41.81 & 16.79 & 12.89 & 18.34 & 22.25 & 40.75 & 18.50 & 0.45 & Overload \\
\hline 2009 & 41.77 & 16.80 & 12.27 & 21.11 & 22.58 & 41.15 & 18.57 & 0.45 & Overload \\
\hline 2010 & 39.17 & 18.18 & 14.87 & 19.47 & 22.83 & 41.44 & 18.61 & 0.45 & Overload \\
\hline 2011 & 38.63 & 18.87 & 13.40 & 19.42 & 22.45 & 41.77 & 19.32 & 0.46 & Overload \\
\hline 2012 & 37.76 & 19.82 & 17.42 & 22.64 & 24.12 & 41.97 & 17.85 & 0.43 & Overload \\
\hline 2013 & 35.82 & 19.22 & 18.34 & 23.00 & 23.98 & 42.16 & 18.18 & 0.43 & Overload \\
\hline 2014 & 36.62 & 19.29 & 18.58 & 23.19 & 24.30 & 42.16 & 17.86 & 0.42 & Overload \\
\hline 2015 & 38.03 & 19.37 & 17.98 & 22.11 & 24.30 & 42.17 & 17.87 & 0.42 & Overload \\
\hline 2016 & 39.56 & 19.76 & 20.81 & 22.81 & 25.73 & 42.65 & 16.92 & 0.40 & Overload \\
\hline 2017 & 37.34 & 20.09 & 20.42 & 24.14 & 25.45 & 42.80 & 17.35 & 0.41 & Overload \\
\hline Mean & 39.16 & 18.62 & 16.29 & 21.05 & 23.62 & 41.76 & 18.13 & 0.43 & Overload \\
\hline
\end{tabular}




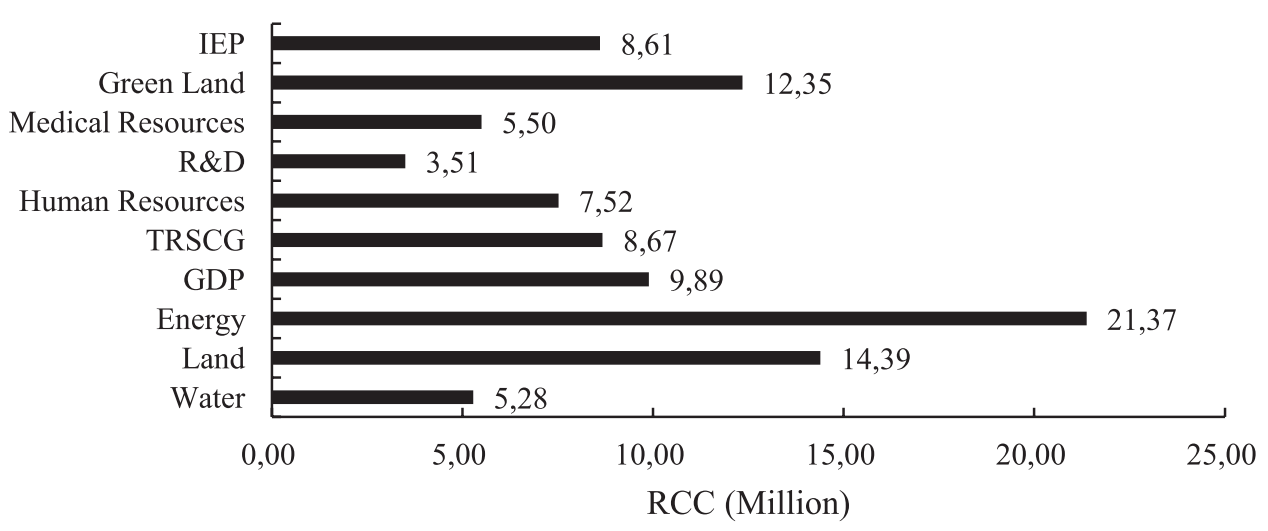

Fig. 2. The average RRCC of each indicator.

IEP: Investment in environmental protection; TRSCG: Total retail sales of consumer goods.

resources, which indicates the importance of human resources in sustainable development. Compared with the social resources, the growth of the RRCC of economic resources was slow. The reason for this trend was that the economic development in most of these cities depended mostly on the mining industry. The reduced production of mineral resources and the single industry model, made it difficult for these cities to achieve substantial economic growth.

\section{Spatial-Temporal Distribution Characteristics of the RRCC}

The ten mining cities were chosen as the reference area, in view of the different levels of development in different regions in the country, 2007 and 2017 were chosen as the study years. The evaluation grades of the RSRCC were divided into five levels including super overload $\left(\mathrm{P}>\operatorname{maxC}_{\mathrm{s}}\right)$; overload $\left(\operatorname{maxC}_{\mathrm{s}}>\mathrm{P}>\mathrm{C}_{\mathrm{s}}\right)$; critical $\left(\mathrm{P}=\mathrm{C}_{\mathrm{s}}\right)$; surplus $\left(\operatorname{minC}_{\mathrm{s}}<\mathrm{P}<\mathrm{C}_{\mathrm{s}}\right)$; super surplus $\left(\mathrm{P}<\min \mathrm{C}_{\mathrm{s}}\right)$. According to Table 5 and Fig. 3, the RRCC of the ten mining cities were diverse. The differences in the carrying states of these cities were highly obvious.

\section{Cities with Super Overload Carrying States}

Fuyang, Bozhou, and Suzhou had RSRCC with the super overload status, and their overload population increased by $19 \%, 19 \%$, and $26 \%$, respectively. These cities are located in the north of Anhui Province and have high carrying capacity of natural resources and economic resources. Among them, Fuyang had the highest population overload of 4.87 million in 2017, although its RSRCC was the largest of the ten cities. The RRCC of natural and economic resources in Fuyang were much higher than those of other mining cities, but they did not equal its population. Similar to Fuyang, Bozhou and Suzhou also had a large population that was higher than the RSRCC, with overload of 2.81 million and 2.6 million, respectively, in 2017. Due to the plain topography, moderate climate, and abundant coal resources in the region, the outputs of grain and coal were very high and the economy was accordingly strong. These conditions lead to the high carrying capacities of natural and economic resources, although they were not high enough to carry the population. The demand for resources in these cities increased due to the enormous number and high growth

Table 5. The RRCC of each mining city in Anhui Province in 2007 and 2017.

\begin{tabular}{|c|c|c|c|c|c|c|c|c|}
\hline \multirow{2}{*}{ City } & \multicolumn{4}{|c|}{2007} & \multicolumn{4}{|c|}{2017} \\
\hline & $\mathrm{C}_{\mathrm{s}}$ & $\mathrm{P}$ & Carrying State & $\mathrm{P}^{\prime}$ & $\mathrm{C}_{\mathrm{s}}$ & $\mathrm{P}$ & Carrying State & $\mathrm{P}^{\prime}$ \\
\hline Fuyang & 5.66 & 9.74 & Super overload & 4.08 & 5.83 & 10.70 & Super overload & 4.87 \\
\hline Bozhou & 3.44 & 5.79 & Super overload & 2.35 & 3.70 & 6.51 & Super overload & 2.81 \\
\hline Suzhou & 4.12 & 6.17 & Super overload & 2.05 & 3.96 & 6.55 & Super overload & 2.60 \\
\hline Maanshan & 4.12 & 2.26 & Super surplus & -1.86 & 4.92 & 2.29 & Super surplus & -2.63 \\
\hline Xuancheng & 4.10 & 2.75 & Super surplus & -1.35 & 4.21 & 2.80 & Super surplus & -1.41 \\
\hline Tongling & 3.12 & 1.70 & Super surplus & -1.42 & 3.12 & 1.71 & Super surplus & -1.41 \\
\hline Huainan & 5.01 & 3.76 & Super surplus & -1.25 & 4.98 & 3.90 & Super surplus & -1.08 \\
\hline Huaibei & 4.05 & 2.14 & Super surplus & -1.91 & 3.18 & 2.17 & Super surplus & -1.01 \\
\hline Chizhou & 1.94 & 1.58 & Super surplus & -0.36 & 2.55 & 1.62 & Super surplus & -0.92 \\
\hline Chuzhou & 3.88 & 4.44 & Super overload & 0.55 & 5.43 & 4.54 & Super surplus & -0.89 \\
\hline
\end{tabular}




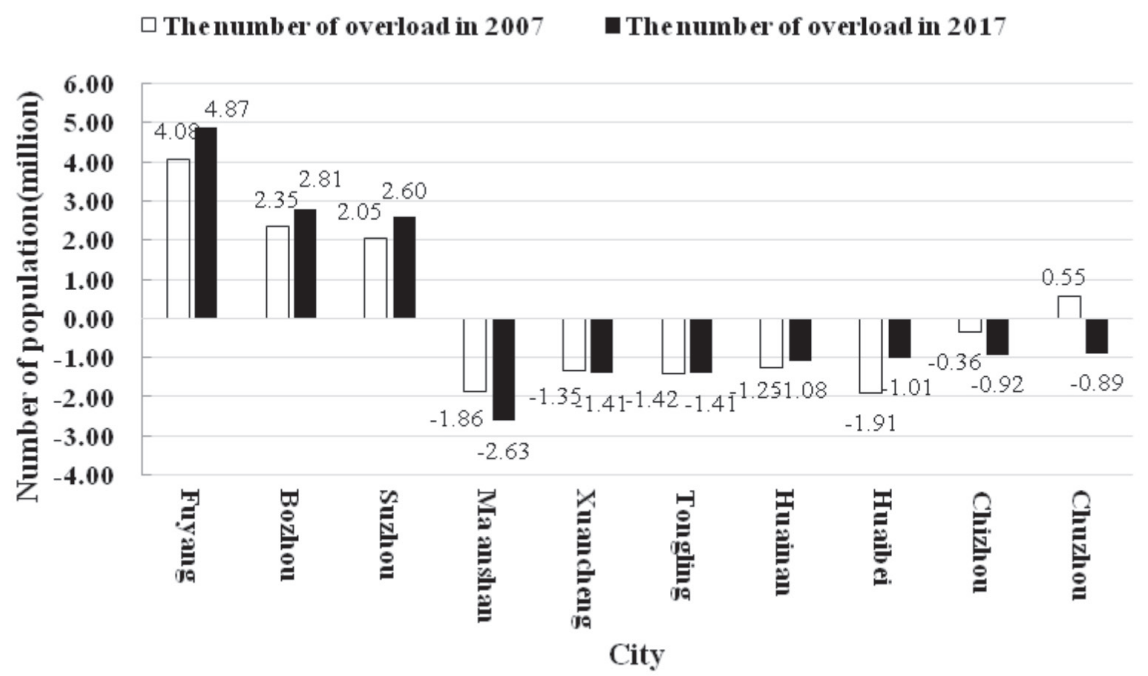

Fig. 3. The number of overload in each mining city in Anhui Province in 2007 and 2017.

rate of population. However, their natural resources, which were the primary resources these cities relied on, decreased considerably. According to our statistics, the total amount of water resources and the total energy production decreased by $85.3 \%$ and $57.4 \%$, respectively. Meanwhile, the growth rates of carrying capacities of other resources were negligible; therefore, the RSRCC did not meet the requirements of the increasing population. Overall, natural and economic resources dominated in the development of these cities, and the exploitation and utilization of social and environmental resources were insufficient.

\section{Cities with Super Surplus Carrying States}

The six cities of Ma Anshan, Xuancheng, Tongling, Huainan, Huaibei, and Chizhou maintained a super surplus carrying state.

Ma Anshan had the highest surplus population, and the surplus scale expanded by $41.39 \%$ in the study years. The RRCC of economic, social, and especially environmental resources of Ma Anshan were in the front row among the ten mining cities. The RRCC of economic resources was 5.17 million, which was 2.88 million more than the actual population in 2017 . Ma Anshan was a typical resource-based city developed on iron ore resources. However, this renewable resource-based city transformed the development model successfully and reduced its dependence on natural resources. Ma Anshan also demonstrated significant progress in economic and social construction; therefore, the RSRCC of this city became much stronger over time. The GDP of this city had been the highest during the studied years. The equipment manufacturing industry, new-energy automobile industry, energy conservation and environmental protection industry, and shipping industry all thrived in Ma Anshan. Meanwhile, the city promoted the development of foreign trade and tertiary industry. These all brought rapid economic growth to this area. The RRCC of social resources was 5.74 million in 2017 which, increased by 1.72 million compared to 2007. In 2017, R\&D expenditures, i.e. the S\&T resources in Ma Anshan was 4.32 billion Yuan. This value was much higher than the mean value of 1.81 billion Yuan of the ten cities. Meanwhile, the carrying capacity of environmental resources was always the highest among these cities. On the one hand, its urban green area was vast; on the other hand, large amounts of money was invested in environmental protection in Ma Anshan, and the city committed to curbing environmental pollution, protecting water sources, and expanding greenbelts and forests. Thus, the environment in Ma Anshan was in good condition, and this benefited the sustainable development of the city.

The surplus population of Chizhou and Xuancheng increased by $156.36 \%$ and $4.27 \%$, respectively. The main mining resource of these two cities was calcite. Chizhou and Xuancheng are located in the south of Anhui Province, which has a dominant topographic of mountains and hills. This topography limited the development of agriculture and industry but facilitated tourism. For Chizhou in 2017, tertiary industry provided $48 \%$ of GDP and the RRCC of environmental resources increased from 118.24 million to 213.25 million $(80.35 \%)$. At the same time, Chizhou had the smallest population and its growth rate was low. Xuancheng's RRCC of natural and social resources increased by more than $20 \%$, but their contributions were lower than that of economic and environmental resources. Notably, the RRCC of environmental resources in Xuancheng decreased by $16.83 \%$.

Although the carrying states of Tongling, Huainan, and Huaibei were at the super surplus status during those years, the surplus scales of the three cities decreased. The RSRCC of Tongling in 2017 was the same as in 2007. As the population increased to 0.01 million, the surplus population decreased by $0.77 \%$. This city had a long history of copper mining 
Table 6 . The functional equation and the value of $p$ and $c$ of GM $(1,1)$ model.

\begin{tabular}{|c|c|c|c|}
\hline Item & Functional equation & Small error probability $(\mathrm{p})$ & Ratio of $\mathrm{S}_{1}$ and $\mathrm{S}_{0}(\mathrm{c})$ \\
\hline Population & $\hat{x}^{(0)}(t+1)=40.7789 * e^{0.005 t}$ & $\mathrm{p}=1$ & $\mathrm{c}=0.1952$ \\
\hline RSRCC & $\hat{x}^{(0)}(t+1)=21.7383 * e^{0.0162 t}$ & $\mathrm{p}=1$ & $\mathrm{c}=0.2907$ \\
\hline
\end{tabular}

and metallurgy, and the copper industry dominated its economy all the time. After more than half a century of large-scale mining, the copper resources in Tongling were depleted, so the city faced a financial crisis. This hindered infrastructure construction and the development of social programs in this city. The RRCC of natural resources were high in Huainan and Huaibei, which meant that natural resources were the main force for development in these regions. As two of the most important coal bases in China, these cities had the largest coal production in Anhui Province. In 2007-2017, natural RRCC in Huainan improved from 5.71 million to 7.49 million and energy resources contributed most to this improvement. At the same time, the RRCC of social and environmental resources declined sharply and the economic RRCC increased only by $3.7 \%$. Unlike Huainan, Huaibei is a resourceexhausted city whose RRCC of natural resources has consistently reduced. With the depletion of coal resources, the disadvantages of a single industrial structure in Huaibei became increasingly apparent, and its RSRCC decreased from 4.05 million to 3.18 million.
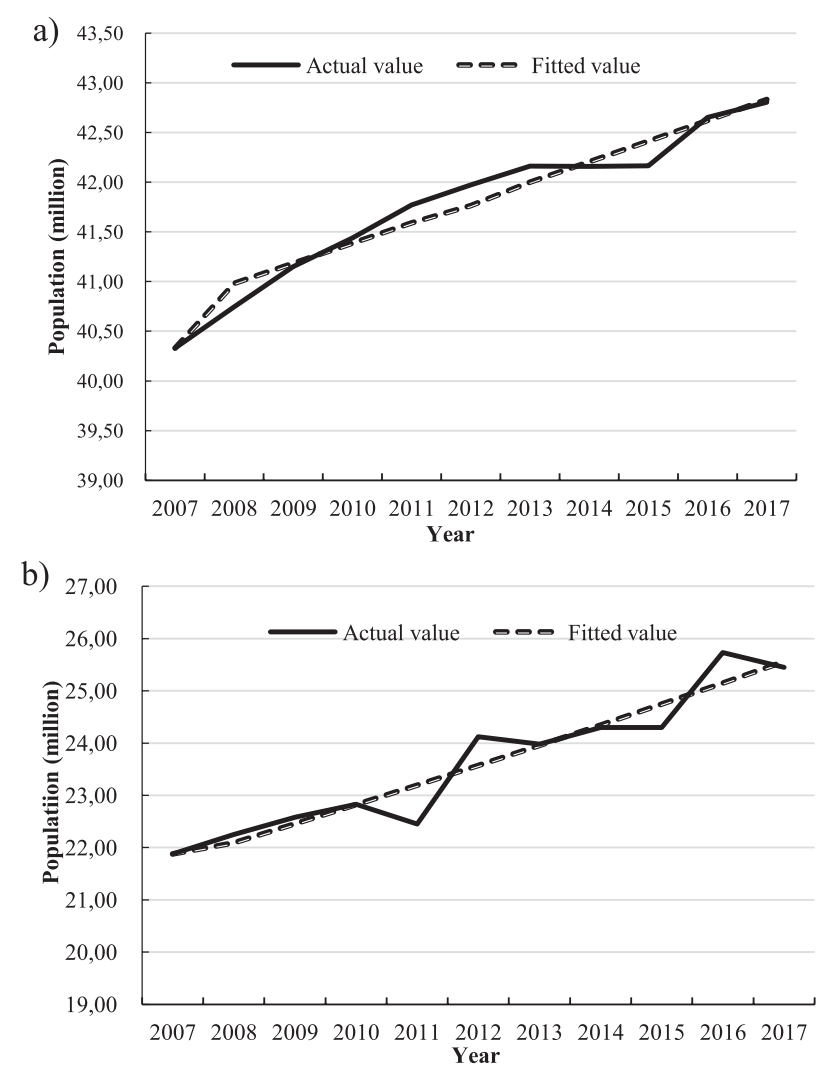

Fig. 4. Fitting situation of population and the RSRCC of the mining cities in Anhui Province from 2007 to 2017.

\section{The City with Changes in Carrying States}

The carrying state of Chuzhou improved from super overloaded to super surplus during the study period. In the light of Fig. 3, the overloaded population of Chuzhou in 2007 and 2017 was 0.55 million and -0.89 million, respectively. Because Chuzhou is close to the Yangtze River delta economic circle, which is the most developed economic center in China, the city experienced rapid growth in its economy in recent years. Except for the traditional nonmetallic mining industry, other pillar industries like advanced equipment, intelligence appliances, silica-based material, and new energy resources were formed. This city attracted high-tech enterprises and talent and invested extensively in technology development and environmental governance. As a result, the RRCC of social and

Table 7. The predicted value of RSRCC of mining cities in Anhui Province in 2018-2023.

\begin{tabular}{|c|c|c|c|c|}
\hline Year & $\mathrm{P}$ & $\mathrm{C}_{\mathrm{s}}$ & $\mathrm{P}^{\prime}$ & $\mathrm{R}$ \\
\hline 2018 & 43.04 & 25.99 & 17.05 & 0.40 \\
\hline 2019 & 43.26 & 26.42 & 16.84 & 0.39 \\
\hline 2020 & 43.47 & 26.85 & 16.62 & 0.38 \\
\hline 2021 & 43.68 & 27.29 & 16.39 & 0.38 \\
\hline 2022 & 43.9 & 27.74 & 16.16 & 0.37 \\
\hline 2023 & 44.11 & 28.19 & 15.92 & 0.36 \\
\hline
\end{tabular}

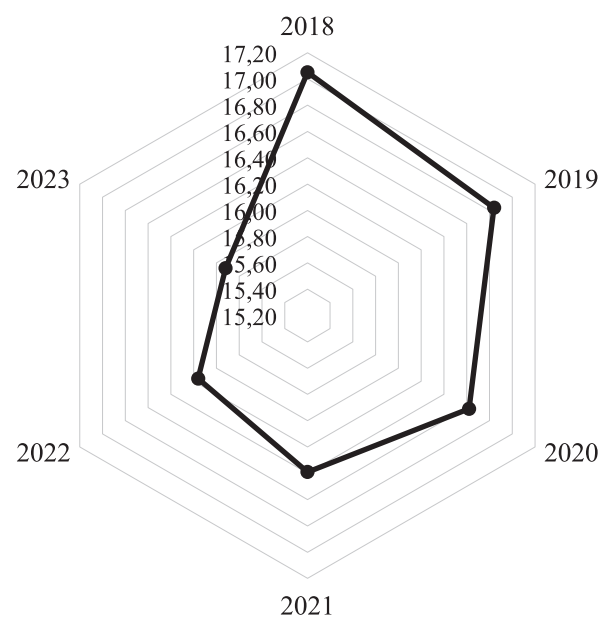

Fig. 5. The predicted changing trend of population overload of mining cities in Anhui Province in 2018-2023. 
environmental resources increased considerably, causing the RSRCC to increase by $39.9 \%$.

\section{The Prediction of the RSRCC}

With the aim to learn the resource carrying situation in the next few years in the study area, GM $(1,1)$ model was used to predict population and the RSRCC from 2018 to 2023. The fitting situation of this model which shown in Table 6 and Fig. 4 was prefect, which meant this model can be used in predicting.

Population and the RSRCC of the ten mining cities in 2018-2023 were predicted respectively by the functional equation in Table 7. In the next six years, the population will grow steadily with the percentage of $2.49 \%$. Meanwhile, the RSRCC would increase from 25.99 million to 28.19 and the percentage is $8.46 \%$, which is higher than that of population. As shown in Fig. 5, the population overload would decrease and the development of these regions would become more rational.

\section{Discussion}

The RRCC of the ten mining cities in Anhui Province was determined while using China as the reference areas. The RSRCC was in an overloaded state from 2007 to 2017; the overloaded population was relatively stable with a slight decrease. The contribution rates of economic, social, and environmental resources were much less than that of natural resources, although their RRCC showed an increasing trend. However, the RRCC of natural resources had constantly declined, which led to a slow growth of the RSRCC. These indicated that the main force supporting the development of these cities was natural resources; however, economic and social progress lagged. Therefore, this mode could not meet the requirement of regional sustainable development. The three indicators with the largest average RRCC were energy, land, and green land; and the three indicators with the smallest average RRCC were R\&D, water, and medical resources.

The RRCC of each city was also obtained by using the ten cities as the reference area. The levels of RSRCC of most cities were relatively stable as time passed but their development situations were different. Fuyang, Bozhou, Suzhou and Huainan are mature or growing coal mining cities that are undergoing massive resource development. The RRCC of natural resources had the largest proportion in these cities. Tongling and Huaibei are declining mining cities facing the pressures of industrial transformation and the RSRCC cannot be easily increased at present. Chizhou and Xuancheng developed third industry during the study period, thus RSRRCC became stronger. Ma Anshan and Chuzhou took advantage of their location, and they fostered hightech industries and promoted environmental protection. These cities successfully reduced their dependence on resources and substantially increased their RSRCC .

The GM $(1,1)$ model was used to predict that the RRCC of these cities would improve and that their population overload would decrease within the next six years. Their development situations might improve, but not well enough.

Based on the RRCC, this study evaluated the sustainable development of mining cities in Anhui Province and analyzed the supportive resources and restrictive resources affecting the progress of these cities. The study improved the evaluation model by adding indicators and selecting the more objective calculation method. Thereafter, the resources carrying situation in the next six years was predicted. Overall, this study complemented and expanded the research on RRCC. Meanwhile, it also provided a reference for evaluating the sustainable development of mining cities. Nevertheless, some details must still be discussed in future studies. Firstly, the evaluation indicators should be chosen according to the characteristics of resources in different study areas. Secondly, the reference area should be determined based on the specific research objects.

In the light of above analysis, it can be known that the current development mode of mining cities in Anhui Province exerts a lot of pressure on resource utilization. Some suggestions targeted at this problem are given as follows.

These mining cities should keep the advantage of mineral resources, exploit the mineral resources rationally, use them efficiently, and develop alternative clean energy to ease the difficulty of limited mineral resource stocks. Meanwhile, water resources and land resources should be protected to ensure the productive capacity of agriculture.

It is necessary for these cities to transform the economic growth mode, foster emerging industries, and strengthen the tertiary industry. Moreover, promoting inter-regional economic activities, undertaking industrial transfer from developed regions, cultivating enterprises suitable for local development are also crucial for these regions.

With the aim to promote the level of education and science research, governmental departments of these cities have to pay attention to increase investment, and bring in talent. On the other hand, they should improve medical conditions and enhance social security benefits to ensure residents' good living conditions.

The relevant government departments have to formulate and implement environmental protection policies and raise residents' awareness of environmental protection to achieve coordinated development of the ecological environment and social economy.

\section{Conclusions}

For the purpose of providing a reference for the sustainable development of mining cities in Anhui 
Province, this study improved the evaluation model of RRCC and analyzed these cities' RRCC and dynamic changes from 2007 to 2017; then predicted the RRCC value in 2018-2023. Results indicated that the RSRCC of most cities was in stable state during the study years, but these cities' carrying situation was not precisely the same.

\section{Acknowledgements}

This work was supported by the following programs: 1. The National Natural Science Foundation of China with the title "Evaluation of Coal Miners' Safety Behavioral Ability and Its Dynamic Pre-warning under the Interaction between Individuals and Environment" (NO. 51574010). 2.Social science innovation and development research project in Anhui with the title "Research on ecological compensation mechanism, path and benefit in middle and lower reaches of Huaihe River" (2019CX110).

\section{Conflict of Interest}

The authors declare no conflict of interest.

\section{References}

1. CHENG J.H., TANG S.Y., WANG X.L., WANG R. China mineral resources development report 2014: evaluation of resource and environment carrying capacity of China's typical mining economic zone. Science press, Beijing, China, 2015.

2. State council. Approval of the state council on the national mineral resources plan (2016-2020). Bulletin of the state council of the People's Republic of China. 33, 39, 2016

3. DONG F., LI J., LI K., SUN Z., YU B., WANG Y., ZHANG S. Causal chain of haze decoupling efforts and its action mechanism: Evidence from 30 provinces in China. Journal of Cleaner Production. 118889, 2019.

4. DONG F., WANG Y., ZHENG L., LI, J., XIE S. Can industrial agglomeration promote pollution agglomeration? Evidence from China. Journal of Cleaner Production. 118960, 2019

5. ZHOU J.H.,WANG L.J.Comprehensive study on ecological restoration and land exploitation of mining subsidence in suburbs of Chinese mining cities. International Journal of Coal Science \& Technology. 1 (2), 2014.

6. LIU W.Y. Evaluation of geological hazard in mining area based on "3S" technology. Coal Science and Technology. 44 (S1), 176, 2016.

7. PARK R.F., BURGESS E.W. An introduction to the science of sociology. The University of Chicago Press, Chicago, IL, USA, 1920.

8. NIU W.Y. Introduction to the sustainable development. Science Press, Beijing, China, 1994.

9. ZHANG G.H., FEI Y.H., LIU C.H., YAN M.J., WANG J.Z. Adaptation between irrigation intensity and groundwater carrying capacity in north China plain. Transactions of the Chinese Society of Agricultural Engineering. 29 (1), 1, 2013.
10. GU K.K., CHU J.L., WANG Y.Z. Spatio-temporal analysis of land use and ecological carrying capacity in coal mining city based on remote sensing. Acta Ecologica Sinica. 34 (20), 5714, 2014.

11. WANG R., CHENG J.H., ZHU Y.L., XIONG W.W. Research on diversity of mineral resources carrying capacity in Chinese mining cities. Resources Policy, 47, 108, 2016

12. ZHANG L.Y., CHUNG S.S., QIU J.W. Ecological carrying capacity assessment of diving site: A case study of Mabul Island, Malaysia. Journal of Environmental Management, 183, 253, 2016

13. HE S.Y., LEE J., ZHOU T., WU D. Shrinking cities and resource-based economy: The economic restructuring in China's mining cities. Cities. 60, 75, 2017.

14. CHEN D., WANG R. Evaluation of resource and environment carrying capacity of mining cities - a case study of Huangshi city. China's land and resources economy. 28 (09), 57, 2015.

15. PENG Z.C., GUO S.L. Research on relative resource carrying capacity in southwest China based on improved model - a case study of Ya'an city, Sichuan Province. Regional research and development. 37, 153, 2018.

16. LI Z.H., DONG S.C., Tang S.Y. Improvement of relative resource carrying capacity model and its empirical analysis. Resources science. 30, 1336, 2008.

17. HUANG N.S., KUANG Y.Q. The relative resource carrying capacity and sustainable development of Guangdong Province. Economic geography. 20, 52, 2000.

18. WANG F., YANG D.G., WANG C.J. Spatio-temporal characteristics of sustainable development in Xinjiang based on improved relative carrying capacity of resources. Journal of Desert Research, 33 (5), 1605, 2013.

19. Yan H. Research on relative carrying capacity of resources of Inner Mongolia. Advanced Materials Research. 726, 4801, 2013.

20. PEI W.T., WANG X.G. Study on the change and sustainable development of relative resource carrying capacity in Tianshui city. Resource development and marketing. 33 (05), 545, 2017

21. YANG J., DING H. A quantitative assessment of sustainable development based on relative resource carrying capacity in Jiangsu Province of China. Int. J. Environ. Res. Public Health. 15, 2786, 2018.

22. LI X.D. Spatial-temporal dynamic change of relative bearing capacity of resources in Wumeng Mountains, Guizhou. Geographical research. 32, 233, 2013.

23. WANG C.J., DU H.R., ZHANG X.L., WANG F., ZHANG L. Relative resource carrying capacity of Tarim River basin. Acta ecologica sinica. 35, 2880, 2015.

24. WANG M., ZHANG X.P. Study on the coupling and coordination between social economy and resources and environment in ecologically fragile areas: a case study of Zhaotong city, Yunnan Province. Journal of university of Chinese academy of sciences. 34 (06), 684, 2017.

25. FU Q., YANG D.G., ZHANG X.H., XIA F.Q., WANG F. Time and space differentiation of relative carrying capacity of resources in Yili based on improved model. Journal of University of Chinese Academy of Sciences. 33 (02), 170, 2016

26. KONG W., ZHANG F., GUO J., OU M.H. Research on regional allocation of incremental construction land with consideration given to economic development and resource endowment. Jiangsu agricultural science. 47 (05), 213, 2019. 
27. LIU Y.H., LIU Y., LI X.B. Reflections on geography in the era of knowledge economy. Journal of geography. 4, 289, 1998.

28. SUN H., LIU Y.Y. Expansion and demonstration of relative resource carrying capacity model. China population, resources and environment. 24, 126, 2014.

29. CHEN Y.Z. Analysis of regional differences in China's relative resource carrying capacity. Journal of social sciences, Jilin University. 4, 111, 2006.

30. HUANG C.F. Improvement of the model of relative resource carrying capacity and its empirical research. Xinjiang University, Urumqi, China, May, 2012.

31. PAN X.P., ZHOU J.S., SHA J.H., XIE C.Y. Evaluation on the development and construction of national mining economic zone in Anhui province. China's mining industry. 23 (09), 53, 2014.

32. LIU Y.J. Study on optimization of modern industrial system in accepting industry transfer in central and western regions-taking Anhui province as an example to undertake industry transfer in the Yangtze River delta region. East China economic management. 27, 28, 2013.

33. XIAO Q.H. Economic analysis of the impact of mineral exploitation on ecological environment in Anhui province. Geology of Anhui province. 13,48,2003.

34. ZENG H.C., YANG Q.Y., LI W.J., XIE Y.Q. Spatial and temporal analysis of the carrying capacity of water resources in Hunan province. Journal of water resources and water engineering. 29 (03), 69, 2018.

35. BING F., CHEN Q.Q., ZHANG D.D. Regional differences of relative resource carrying capacity in grassland pastoral areas in Gansu province. Pratacultural science. 33 (12), 2587, 2016.

36. CHEN W.X., LI J.F., WU K., FAN X. Construction and empirical analysis of the evaluation model of relative resource carrying capacity in Xinjiang. Arid Land Geography. 40, 453, 2017.

37. CHEN Y.J., YI X.Y., FANG L.N., LI Q.Q. Analysis of cultivated land resources and grain production capacity in China. Agricultural resources and regionalization in China. 33 (06), 4, 2012.

38. HUANG C.F., HE L.Z., LIU L. Research on relative resource carrying capacity model. Economic geography. 30 (10), 1612, 2010.

39. DE CAIGNY A., COUSSEMENT K., DE BOCK K. W. A new hybrid classification algorithm for customer churn prediction based on logistic regression and decision trees. European Journal of Operational Research. 269, 2018.
40. TORABI A., MOUSAVY S.A.K., DASHTI V., SAEEDI M., YOUSEFI N. A new prediction model based on cascade $\mathrm{NN}$ for wind power prediction. Computational Economics. 53, 2019.

41. CALHEIROS R.N., MASOUMI E., RANJAN R., BUYYA, R. Workload prediction using ARIMA model and its impact on cloud applications' QoS. IEEE Transactions on Cloud Computing. 3 (4), 449, 2017.

42. HAU C.C., CHEN C.Y. Applications of improved Grey prediction model for power demand forecasting. Energy Conversion and Management. 44 (14), 2241, 2003.

43. TANG W.M. Research of some forecasting methods and models. Inner Mongolia University, Hohhot, China, April, 2012.

44. ZHOU W., HE J.M. Generalized GM $(1,1)$ model and its application in forecasting of fuel production. Applied Mathematical Modelling. 37 (9), 6234, 2013.

45. HAN F.S., ZHANG Y. Prediction of environmental carrying capacity for Chinese cities based on artificial neural network and Grey model GM $(1,1)$ prediction. Journal of Computational and Theoretical Nanoscience. 13 (9), 6372, 2016.

46. XU L.L., LI H., LI J. Population prediction based on Grey prediction and radial basis network. Computer science. 46 (S1), 431, 2019.

47. YANG X., ZOU J., KONG D., JIANG G. The analysis of GM $(1,1)$ Grey model to predict the incidence trend of typhoid and paratyphoid fevers in Wuhan City, China. Medicine. 97 (34), e11787, 2018.

48. SUN J., WANG C., HU L. Wind power generation prediction based on the combination of modified Grey model and BP neural network model. Hydropower energy science. 33 (04), 203, 2015.

49. SHI G.S., WANG C.S., GANG Z.Y., RAN X.Y. Prediction of coal and gas outburst intensity in Xinan coalfield based on Grey-neural network. Safety in Coal Mines. 46 (09), 166, 2015.

50. SONG Z.Y., ZHANG G.Y., SU Y.Q. One fusion algorithm of equipment fault prediction based on rough set theory and Grey model. Applied Mechanics \& Materials, 687, 1377, 2014.

51. XU M., LIU C.L., LI D., ZHONG X.L. Tourism ecological security early warning of Zhangjiajie, China based on the improved TOPSIS method and the grey GM $(1,1)$ model. The journal of applied ecology. 11, 284, 2017. 
